\title{
Dual Dimensions of VR Education Development: Vision and Technology Direction
}

\author{
Kangkai YANG \\ Chongqing University of Arts and Sciences, Chongqing 402160, China
}

Keywords: Internet plus; VR; education fairness; immersive feeling; technical ethics

\begin{abstract}
The visual display characteristics of VR have changed the flatness of knowledge in traditional education, and its immersion characteristics and students' learning process can produce good fusion, VR can change students' alienation of technology and learning process in the classroom. There is close association logic between VR system and modern educational technology platform and classroom, simultaneously, it also accelerates the redistribution of educational resources and promotes the realization of education fairness. Experience and interest are procedural goal of VR education pursued, but in reality, the idea of parents, teachers and students, and the development of VR hardware level and scarcity of education content hinder the development of VR education, technology and demand for talented persons will be the key for VR education development in the future. VR has the potential to become a standard tool in the field of education, and educational content can be re-created using VR technology to form a new VR education ecosystem.
\end{abstract}

The deep involvement of technology and the systematic reconstruction of education have brought more diverse teaching and learning changes through the rotation. Horizon Report (2016 Higher Education Edition) regards VR technology as the key technology to resolve deep learning contradictions in the next 2-3 years. VR technology brings high immersion and fun to students, making it the most promising star technology in education after multimedia and Internet, it has largely subverted the traditional teaching methods, and deeper educational sources problem will likely be touched.

\section{A New Vision of VR Technology and Education}

Around 2009, the era of consumption of mobile intelligent terminal devices based on traffic dividends entered a recession stage. Application technologies with more innovative concepts have spawned two major industrial innovation directions: VR and IOT, which have triggered the basic entrepreneurial and employment situation of the VR industry. 2016 was called the first year of VR industry, and huge amounts of capital poured into the VR industry. According to the forecast of the multinational investment bank Goldman Sachs Group in early 2016, the global VR market revenue scale is expected to soar to 60 billion US dollars in 2025. China's huge market capacity will make it the main force in the global VR market. The British magazine Economist wrote that China is leading the world in the VR popularization $^{[1]}$.

The synergy between education and technology can change the world we live in. The popularization of VR+ education has caused students to change their understanding of learning. A Samsung survey on VR in the United States shows that 85\% of teachers believe that the use of VR technology in the internet plus era can improve students' learning efficiency in teaching ${ }^{[2]}$. The significance of education is to enhance the richness of students' life experience. The participatory learning process makes personalized education truly a reality. The VR system built on the internet has made education alive, and it has brought a new vision of education in the cultivation of artisan spirit, student scene knowledge learning and learning resources. VR has brought a new educational technology revolution.

\section{The Logic of VR System and Modern Education}

“Internet plus" represents a new way of life, new ecological concept and new economic format. Human-computer interaction under the "Internet plus education" model has had a tremendous impact on 
the original education model and concept of educating people. In the "internet plus" education model, the school pays more attention to the improvement of students' organizational coordination, information acquisition, learning ability and international vision. Students can access various learning materials conveniently and quickly through the online platform ${ }^{[3]}$. VR education based on internet plus not only changes the knowledge production mode, but also provides a new tool for pushing education fair from theoretical design to reality.

\subsection{The logic of VR and modern educational technology platform}

The modern educational technology platform is born out of the traditional educational media, and has experienced the development process of single media text, media-compliant audiovisual technology, and interactive media multimedia technology. As a highly immersive media, VR has three basic features of immersion, interaction and conception. These features enable the full play of human subjects and achieve breakthroughs from 2D to 3D $\mathrm{D}^{[4]}$. VR education can be seen as an extension of "internet plus education" or as one of the support points of "internet plus education", With the help of VR technology, students become the active constructors of knowledge learning by the onlookers of knowledge learning, and their thinking becomes fine, infiltrates the professional attitude of excellence and the creative spirit of pursuing skill. The experience and fine thinking in VR education set up a technology platform for the cultivation of "artisan" innovative talents.

The application of VR in modern education is the accumulation of knowledge and technological ability in the development of educational technology, Its integration with Internet technology is a milestone in the modern educational technology platform. The technology platform is a key external factor for students' learning, deep integration of VR and education will lead to a new educational revolution, inheriting tradition and keeping up with the times, and promoting the realization of innovation-driven strategy through synchronization with technological development.

\subsection{The logic of VR and modern classroom}

The core of education is to effectively motivate students and form "positive feedback" in learning as soon as possible. The traditional classroom teaching method is teacher-led. The panoramic teaching mode based on VR immersion and interactivity can bring students a scene-like experience, especially in some scenarios that require practical operation. A realistic learning environment allows students to gain unlimited immersive virtual experiences across a wide range of scientific fields, it can greatly stimulate students' interest in active learning, thus accelerating and consolidating the process of students' knowledge learning ${ }^{[5]}$. Virtual teaching presents the original and difficult textbook knowledge in an intuitive and vivid three-dimensional image, which enables students to have close contact and experience in close proximity, and has the advantage that traditional teaching is incomparable.

The new learning method in which learners acquire knowledge and skills through their interaction with the information environment replaces the traditional "teaching and learning" learning style, which is revolutionary for human learning technology ${ }^{[6]}$. The immersive scene provided by VR can effectively overcome the monotony of the educational scene, make the teaching activities more vivid, and further confirm the student's subjective status. Contextual learning can promote knowledge expression and application, and has a great influence on cultivating students' core literacy, scientific research, engineering practice and thinking ability, innovative thinking and exploration spirit.

\subsection{The logic of VR system and fair education}

The essence of educational equity is fair distribution of educational resources, and its realization requires the dual adjustment of the internal and external relations of the education system. The dominant players in China's education have changed from a monopoly in the past to a state control, a combination of market mechanisms and group choices, and educational resources are also characterized by differentiation and diversity. Digital education resources have become an important component. The rise of virtualization technology and cloud computing technology has provided a new carrier for educational resource sharing. The establishment of sharing platform has created an excellent supportive environment for education fairness and accelerated the redistribution and balance of educational resources. The sharing platform of digital education resource realizes the sharing of educational resources by continuously 
expanding the coverage of resources, effectively solving the problem of excessive over-building of educational resources and low circulation and sharing, and gradually narrows the contradiction between educational developed areas and relatively backward areas, urban and rural educational resources, thereby achieves the fairness of education. Educational resources are shared through technology, which provides a resource choice space for all in theory. Any student can enjoy quality educational resources and change educational inequalities in a technologically innovative way. In addition, VR technology combined with online courses, learners can learn anytime and anywhere, lifelong education are truly possible, and students ultimately achieve free and comprehensive development ${ }^{[7]}$.

\section{The Real Dilemma Facing the Modernization of VR Education}

Using VR technology to reconstruct educational content, transform educational technology, and reshape education idea, we call it VR education. The history of VR education in China is very short, and the future is bright but the weakness is obvious. There are many reasons for this phenomenon, both at the conceptual level and the reasons for the imperfections of the technology itself.

\subsection{VR education raises social concerns about students' interpersonal and psychological problems}

VR application to education has its philosophical and scientific foundation. The ancient Chinese thinker Xunzi explored the learning style, and he said that hearing is better that nor hearing, seeing is better than hearing, knowing is better than seeing, dong is better than knowing, and learning and doing it is the best. The theory of learning pyramid advocated by American educator Edgar Dell believes that, the memory ability of human beings is closely related to the way information is provided. After two weeks, the memory in the human brain can still be preserved, accounting for $10 \%$ of what is seen, $20 \%$ of what is heard and $90 \%$ of what is experienced ${ }^{[8]}$.

VR education emphasizes that students are the main body of learning process, the active constructor of knowledge meaning, and an effective way to cultivate creative talents. Education is a bilateral social activity in which teaching and learning interact. Students' self-directed learning will reduce the leading role of teachers to a certain extent, leading to emotional alienation between teachers and students. At the same time, it will also affect the teaching effect of emotional goals such as moral emotion, physical and mental health and social ability. If the degree of freedom of students' self-learning is too large, it will deviate from the teaching goal. Limited by the designer's presupposition, VR can't exhaust all the problems in reality. In addition, VR education requires strong self-control. For students with poor self-control ability, using VR technology for teaching will obviously encounter some practical dilemmas in teaching scenes.

\subsection{Educational stakeholders have limited awareness of VR education}

In recent years, although China has carried out diversified exploration and practice in the enrollment system, the main system of talent selection is still based on examinations. Many parents' perceptions of VR education are still in the initial stage. In the eyes of ordinary people, VR education is still high-tech. Based on traditional cognition, VR openness and immersive characteristics can cause parents and teachers to feel distrustful. The fascination with the way traditional knowledge is transmitted makes them wonder whether students can really learn in virtual reality, worrying those students will be lost in the virtual world and reduce their recognition of the real world.

Some developed countries such as the United States have already fully implemented VR education in basic education, but at this stage, a large number of people in China still lack forward-looking knowledge. The education administrative department is the master and dominator of resources, and its awareness of VR education directly affects the popularity and development of VR education. In the areas where economic conditions and educational conditions are relatively backward, many people themselves have not experienced the impact of VR, so they are not interested in VR.

\subsection{The lack of resource pool is a shortcoming to the development of VR education}

The quality of education depends first and foremost on the provision of educational content, and good content can be accepted and respected by the public. The generation of 3D stereoscopic images in a VR 
device requires first processing the image and then transforming the image by sensory signals received from the human body, and this requires a huge storage area to achieve. VR education has not yet established a huge resource repository, and unable to provide users with a broad choice of space. If the students' demands for knowledge are not satisfied in the process of using the products, and the rich content is not experienced, it will inevitably affect the recognition of VR education, and it is more difficult to promote the large-scale promotion of VR education. The development of VR educational content requires a solid foundation of VR technology, solving technical problems such as delay and expression capture, as well as profound teaching resources and curricul um design capabilities to complete VR education products. The implementation of VR education content requires teachers to fully control the teaching progress in the VR classroom, calculate the VR learning effect of the students in time, and finally reach the students according to their aptitude. There is poor talent reservation in technology development and application at present. VR educational content needs a lot of rendering to achieve immersion effect, and the production cost is much higher than traditional content production. Moreover, the VR industry is still in the seed user training stage, and the user base is too small, which makes the content production team unable to make profits ${ }^{[9]}$, and these factors lead to a long way to go for the ecological construction of VR education.

\subsection{Incomplete hardware is a serious injury to the development of VR education}

The use of technology requires the corresponding hardware as a carrier. At this stage, the VR "ecosphere" is still in the initial state, and the hardware of VR is still not perfect, related algorithms and theories are not mature enough in new sensing mechanisms, collection and physical modeling methods, high-speed graphics and image processing, artificial intelligence and other fields. In recent years, VR hardware technology has certain innovations, but most products have insufficient resolution and refresh rate, users will have dizziness when using VR reality device hardware for a long time. The combination of technology and products can achieve market effects. Currently, there are different types of VR hardware on the market, the technical levels are different, and most of the hardware is not compatible with each other. Providing the best experience for users at the lowest cost is the core and necessary way of product iteration, hardware hardship affects the sustainable development of VR education.

\section{Conclusion}

Constrained by various factors such as cognition, although some educators believe that VR education is another form of traditional "instillation" education, the novel experience that students acquire is to facilitate understanding of the content of the textbook and to receive more information, VR just innovated the way to show the content of learning, and did not get rid of "instillation" in the bones. But no matter what, VR can bring a high-quality learning experience after all, and it has already possessed revolutionary features. This cross-regional resource sharing will make school education a new attitude.

The essence of VR technology is the "world" that can be freely interacted through the integration of cross-border artificial intelligence, big data and pan-industrial networks, realizes the natural interaction between the virtual world and the real world, and its technology development trend will be toward low-cost rapid modeling technology, real-time 3D graphics generation and display technology, development of new interactive devices, intelligent and natural VR modeling, and development of distributed VR technology. With the development of technology and the richness of content, VR will become a revolutionary technology that affects all fields. In the future, it may be possible to directly manipulate the real world with vision, gestures and voice, just like people communicating with others. Correspondingly, the demand for VR talents will be developed in a blowout manner, and this will bring new opportunities to the professional development of universities. Any subject with visual characteristics can be re-created using VR technology. With the injection of new educational content, the combination of various detailed elements of education resources will become the norm. In the future VR education ecosystem, more attention will be paid to user scenarios, teaching quality and user experience. 
The essence of VR applying in education is not how to add a new media technology, but to create a better teaching method by combining this new technology, the degree of classroom VR will become one of the reference standards of school strength, which is also the difficulty and focus of VR technology applied to education. Collaboration in the VR classroom can promote the integration of students who are obsessed with internet, and these students will be accepted by the students because of their technical expertise. The way VR education teaches will be a positive and attractive experience for students, and any physiological characteristics of students are not related to their acceptance of VR educational content, the participation of VR will make their exploration desires finally turn to learning and thinking. VR technology creates the world of imagination, and the safe working environment created by the virtual platform is the best choice to release students' creativity.

VR technology solves the requirements of contextualization and interactivity in the learning process, enabling students to acquire perceptual and rational understanding of the objective world and things from a specific integrated virtual integrated environment, and build a new sense of innovation, and this will greatly narrow the gap between education and current social learning needs. Although early VR-related research has touched the impact of students' sense of presence, psychological experience, and availability of virtual reality learning environments on student learning outcomes, how to reduce the negative impact of VR education, and the impact of VR on the real world and the technology that is triggered ethical issues, people need to deepen their understanding in order to gradually solve.

\section{Acknowledgment}

*This research is supported by H\&S Sciences Research Planning Fund(18YJA880002) and Chongqing University of Arts and Sciences(2017ZJY31)

\section{References}

[1]. Z. J. Liao, “Chinese electronics products go to the high-end market”. People's Daily, 2017-01-06 (03).

[2]. VR education has become a new model under "Internet + education"[EB/OL].[2018-09-28].http://www.vr.cn/article/4027. html.

[3]. Y. S. Wang, Correct Understanding of the Influences of Network Information Technology on the University Teaching and Learning, Chongqing Higher Education Research, 2017, 5 ,(1):9-13.

[4]. W. C. Luo, The virtual reality technology and the talents training of “emerging engineering”- taking Chongqing University of Arts and Sciences as an example, Chongqing higher education research, 2018, 6(1):65-77.

[5]. Y. M. Shen, Y. Chen, Y. Yang, Construction of High Simulation Informationized Accounting Practice Teaching Platform, Business Culture, 2012(4):223-224.

[6]. M. D lv, C. R. Meng, Exploring the important role of virtual reality technology in interior decoration materials and construction courses, Modern decoration, 2015(2):22-23.

[7]. X. Y. Ma, W. P.Shi, Value Logic and Action Strategy of VR/AR Technology in the Field of Vocational Education, Chinese Vocational and Technical Education, 2017(30):42-47.

[8]. D. Edgar. Audiovisual, methods in teaching, New York: Dryden Press,1946: 291-298.

[9]. Y. C. Sun, Y. X. Wang, S. R. Zhu, etc. The development and dilemma of virtual reality technology in education, Journal of Higher Education, 2017(4):193-194. 